\title{
Sex influence on genetic expressions of early growth in Afshari lambs
}

\author{
F. Ghafouri-Kesbi ${ }^{1}$ and D. R. Notter ${ }^{2}$ \\ ${ }^{1}$ Department of Animal Science, Faculty of Agriculture, Bu-Ali Sina University, Hamedan, Iran \\ ${ }^{2}$ Department of Animal and Poultry Sciences, Virginia Tech, Blacksburg, VA 24061, USA \\ Correspondence to: F. Ghafouri-Kesbi (f.ghafouri@basu.ac.ir)
}

Received: 30 August 2015 - Revised: 29 November 2015 - Accepted: 11 December 2015 - Published: 15 January 2016

\begin{abstract}
Very little is known about the genetic aspects of sexual dimorphism of body weight in domestic sheep, and therefore this study was conducted to quantify the genetic basis of sexual dimorphism for earlygrowth-related traits in Afshari lambs. Traits evaluated included birth weight (BW), weaning weight (WW), and growth rate (GR) in male and female lambs. Male lambs were $6.6 \%$ heavier at birth, had $14.4 \%$ higher preweaning growth rates and were $16.0 \%$ heavier at weaning compared to female lambs. Levels of sexual-size dimorphism (SSD), expressed as the ratio of male to female means, for BW, WW and GR were 1.07, 1.14 and 1.15 , respectively, which indicated low levels of SSD in the traits studied. Fixed effects of year of birth and type of birth interacted with sex effects, with greater variability in birth and weaning weights among years and birth types in male lambs, suggesting greater environmental sensitivity in the males. Bivariate animal models and restricted maximum likelihood (REML) procedures were used to estimate phenotypic variances and their genetic and non-genetic components in male and female lambs. Estimates of the direct heritability $\left(h^{2}\right)$ and additive coefficient of variation $\left(\mathrm{CV}_{\mathrm{A}}\right)$ for $\mathrm{BW}$ were higher in males. However, for WW and GR, heritability estimates were higher in females. In contrast, whereas the contribution of maternal permanent environmental effects $\left(c^{2}\right)$ to variation of BW was higher in females, for WW and GR higher estimates of $c^{2}$ were observed in males. Respective genetic and maternal permanent environmental correlations between records on males and females were 0.986 and 0.723 for BW, 0.995 and 0.983 for WW, and 0.995 and 0.966 for GR, indicating possible sexual dimorphism only for maternal effects on BW. Based on an approximate $95 \%$ confidence interval, none of the observed differences in variance components between sexes differed from zero and none of the observed genetic or maternal correlations differed from 1.0, indicating no need or opportunity for sex-specific selection strategies.
\end{abstract}

\section{Introduction}

Sexual-size dimorphism (SSD), i.e., size differences between conspecific males and females, is common in the animal kingdom and particularly marked in the mammalian species, both in wild and domestic populations (Milner et al., 2000; Poissant et al., 2008; Polak and Frynta, 2009, 2010; Gudex et al., 2009). The SSD is the outcome of combined effects of several factors such as specific selection pressure, sex-biased phenotypic and genetic variation, and it may also reflect an imperfect genetic correlation between sexes for body size (Badyaev, 2002). In a group of related species, SSD is often larger in larger species and decreases as the size of species decreases. This phenomenon is termed Rensch's rule (Rensch, 1950). In addition, in related species, SSD is normally more pronounced in wild, compared to domestic, species because of the reduced role of male combat in captive herds; the effect of reduced sexual segregation in captivity, where males usually graze together with females in mixed herds; and relaxed intrasexual selection as a result of the femalebiased operational sex ratio (Polak and Frynta, 2009).

The Afshari sheep breed is one of the heaviest and largest mutton breeds in Iran and is widely distributed in mountainous areas in the west of the country. Today, a large percentage of the Afshari sheep population is raised in Zan- 
Table 1. Pedigree structure of the Afshari sheep.

\begin{tabular}{lr} 
Number of animals in the pedigree file & 1731 \\
Number of base animals & 235 \\
Number of animals with progeny & 575 \\
Number of animals without progeny & 1156 \\
Number of sires with progeny & 49 \\
Number of dams with progeny & 526 \\
Number of animals with unknown mother & 0 \\
Number of animals with unknown father & 5 \\
\hline
\end{tabular}

jan province. The Afshari is a fat-tailed, carpet-wool sheep with brown color and is primarily used for meat production (Eskandarinasab et al., 2010). In Afshari sheep, there are distinct differences in growth pattern between sexes: male lambs are heavier at birth, grow faster in all growth phases, and tend to be leaner than females. On average, mature Afshari rams are over $25 \%$ heavier than mature ewes (66 vs. $53 \mathrm{~kg}$ ).

Although SSD is apparent in domestic animals such as sheep (Gudex et al., 2009), goat (Polak and Frynta, 2009), pig (Dunshea, 2001), cattle (Polak and Frynta, 2010), rabbit (Eason et al., 2000) and chicken (Maniatis et al., 2013), little effort has been made to investigate its genetic basis and explore its potential use in sheep breeding programs. Accurate estimation of breeding values and the definition and realization of optimal multiple-trait selection response for each sex are challenges when SSD is present in sheep production, especially if heritabilities for measures taken on males and females are unequal and (or) genetic correlations between the sexes are less than unity (Gudex et al., 2009). For this reason, the present study was designed to investigate phenotypic and genetic differences in body weights between male and female Afshari lambs and estimate the genetic correlation between sexes.

\section{Material and methods}

\subsection{Study area and flock management}

The flock was established in 1998 and maintained as a closed flock. Animals were maintained by the Department of Animal Science of the University of Zanjan, Zanjan, Iran. The farm is located $1663 \mathrm{~m}$ above mean sea level and at $35^{\circ} 35^{\prime} \mathrm{S}$ and $47^{\circ} 15^{\prime} \mathrm{E}$. This location has temperate summers and cold winters, and an average annual rainfall of approximately $360 \mathrm{~mm}$. Animals were maintained under environmental, nutritional and management conditions that reflected the local environment. The mating season was in October and November of each year, with groups of 10 ewes exposed to a single fertile ram in separate mating pens. Lambing therefore took place in March and April. Lambs were weighed and identified with numbered plastic ear tags within $24 \mathrm{~h}$ of birth. Sex, birth date, birth type, dam ID and sire ID were recorded and stored in a database. Male lambs all remained intact. The suckling period lasted for an average of 120 days, with a range between 98 and 144 days. During the suckling period, lambs received all the milk produced by their dams and were allowed access to grass hay after 1 month of age. After weaning, ewes and young animals were maintained on natural pasture as separate flocks. Range conditions were poor during the late autumn and winter months. Animals were therefore kept indoors from December through March and manually fed according to NRC (1985). Animals were shorn annually in June. Ewes were kept in the flock for a maximum of six parities; however, ewes that did not lamb in any season or were ill were culled sooner. Rams were used for three breeding years.

\subsection{Evaluated traits}

Data used for this study included body weight at birth (BW) and weaning weight (WW). Weaning weights were adjusted to 120 days of age by adding 120 times the preweaning average daily gain to birth weight. The total weight gain from birth to weaning was calculated and subsequently used to calculate the growth rate (GR) as total gain divided by the age at weaning. Tables 1 and 2, respectively, show the characteristics of the pedigree and data used in the analyses. As shown, the quality of pedigree was high. All dams were recorded, and only five animals had unknown sires.

The SSD was expressed using the Lovich and Gibbons ratio (Lovich and Gibbons, 1992) of M / F for species in which the males are larger (as they were in this study) or of $\mathrm{F} / \mathrm{M}$ for species in which female are larger; $\mathrm{M}$ and $\mathrm{F}$ are means for male and female body weights, respectively.

\subsection{Statistical analysis}

To identify fixed effects, least-squares analyses were conducted using the General Linear Model (GLM) procedure (SAS, 2004) with a model that included fixed effects of year of birth; age of dam at lambing; type of birth; and sex-year-of-birth, sex-type-of-birth and sex-age-of-dam-atlambing interactions. In bivariate analyses the effect of sex of lambs together with the corresponding interactions were dropped from the model. Multiplicative adjustment factors to correct traits measured in twins and triplets to a singlelamb basis were calculated by dividing least-squares means of traits measured in single lambs to similar traits measured in twins and triplets. (Co)variance components and genetic parameters were estimated using the DFREML program of Meyer (2000). Recorded traits were related to early growth, and maternal effects were therefore expected to be important. Maternal effects can arise from additive genetic differences expressed in related dams, permanent environmental maternal effects associated with repeated lambings, and litter effects associated with full-sib littermate lambs. However, separation of these different sorts of maternal effects is difficult, requiring deep and well-structured pedigrees with rel- 
Table 2. Characteristics of the data structure.

\begin{tabular}{lcccccc}
\hline Item & \multicolumn{5}{c}{ Trait } \\
\hline & \multicolumn{2}{c}{ GR, g day ${ }^{-1}$} & \multicolumn{2}{c}{ WW, kg } & \multicolumn{2}{c}{ BW, kg } \\
\cline { 2 - 7 } & Female & Male & Female & Male & Female & Male \\
\hline Number of records & 748 & 747 & 688 & 711 & 688 & 711 \\
Number of sires with progeny & 47 & 47 & 47 & 47 & 47 & 47 \\
Number of dams with progeny & 385 & 369 & 369 & 369 & 374 & 369 \\
Average number of progeny per sire & 15.8 & 14.5 & 14.5 & 14.5 & 15.8 & 15.1 \\
Average number of progeny per dam & 1.9 & 1.8 & 1.8 & 1.8 & 1.9 & 1.9 \\
Mean & 182 & 4.966 & 4.657 & 30.287 & 26.474 & 210 \\
SD & 0.643 & 0.614 & 5.619 & 4.499 & 44 & 35 \\
CV (\%) & 12.94 & 13.18 & 18.55 & 16.99 & 21.03 & 19.10 \\
\hline
\end{tabular}

BW: birth weight; WW: weaning weight; GR: growth rate; SD: standard deviation; CV: phenotypic coefficient of variation.

atively large groups of half-sib dams, reasonably large numbers of lambings by individual dams, and substantial numbers of twin and triplet litters. In particular, estimation of separate genetic parameters for lambs of each sex in our study halved the average numbers of progeny per dam and per litter, which would further complicate partitioning of maternal effects. Albuquerque and Meyer (2001) reported that fitting only an additive genetic or permanent environmental maternal effect generally accounted for the total maternal variation arising from both sources. The component that should be fitted would be the "one which is less sensitive to data structure" and would normally be the maternal permanent environmental effect. Also, for our data, litter effects could only be estimated from litters containing two or more lambs of the same sex. These restrictions led us to conclude that a model that only included additive direct and maternal permanent environmental effects was most appropriate for these data.

We first fitted a univariate animal model including lambs of both sexes, and with sex effects included in the model, to provide baseline estimates of variance components and genetic parameters under the assumption that sex effects do not influence these parameters. Following this, a bivariate model was fitted including observations on males and female lambs as different traits. The bivariate model was

$$
\begin{aligned}
{\left[\begin{array}{l}
\boldsymbol{y}_{1} \\
\boldsymbol{y}_{2}
\end{array}\right] } & =\left[\begin{array}{cc}
\mathbf{X}_{1} & \mathbf{0} \\
\mathbf{0} & \mathbf{X}_{2}
\end{array}\right]\left[\begin{array}{l}
\boldsymbol{b}_{1} \\
\boldsymbol{b}_{2}
\end{array}\right] \\
& +\left[\begin{array}{cc}
\mathbf{Z}_{a_{1}} & \mathbf{0} \\
\mathbf{0} & \mathbf{Z}_{a_{2}}
\end{array}\right]\left[\begin{array}{l}
\boldsymbol{a}_{1} \\
\boldsymbol{a}_{2}
\end{array}\right] \\
& +\left[\begin{array}{cc}
\mathbf{Z}_{c 1} & \mathbf{0} \\
\mathbf{0} & \mathbf{Z}_{c_{2}}
\end{array}\right]\left[\begin{array}{l}
\boldsymbol{c}_{1} \\
\boldsymbol{c}_{2}
\end{array}\right]+\left[\begin{array}{l}
\boldsymbol{e}_{1} \\
\boldsymbol{e}_{2}
\end{array}\right],
\end{aligned}
$$

where subscripts 1 and 2 pertain to male and female traits, respectively; $\boldsymbol{y}_{1(2)}$ is $n_{1(2)} \times 1$ vector of observations; $\boldsymbol{b}_{1(2)}$ is a $p \times 1$ vector of fixed effects, where $p$ denotes the total number of fixed effect classes; $\boldsymbol{a}_{1(2)}$ is a $q \times 1$ vector of additive genetic effects, where $q$ denotes the total number of animals in the pedigree; $\boldsymbol{c}_{1(2)}$ is a $k \times 1$ vector of maternal permanent environmental effects, where $k$ is the number of dams with offspring; $\boldsymbol{e}_{1(2)}$ is an $n_{1(2)} \times 1$ vector of residuals corresponding to temporary environment effects; and $\mathbf{X}_{1(2)}$, $\mathbf{Z}_{a 1(2)}$, and $\mathbf{Z}_{c 1(2)}$ denote incidence matrices relating observations to fixed, additive animal, and maternal random effects, respectively. Direct additive genetic, maternal permanent environmental, and residual effects were assumed to be normally distributed with mean 0 and variances $\mathbf{A} \sigma_{\mathrm{a}}^{2}, \mathbf{I}_{\mathrm{nd}} \sigma_{c}^{2}$, and $\mathbf{I}_{e} \sigma_{e}^{2}$, respectively, where $\mathbf{A}$ is the additive numerator relationship matrix containing individual elements $A_{i j}=2 \Theta_{i j}$ and $\Theta_{i j}$ is the coefficient of co-ancestry (kinship) between individuals $i$ and $j ; \mathbf{I}_{\text {nd }}$ and $\mathbf{I}_{e}$ are identity matrices of order equal to the number of dams and number of records, respectively; and $\sigma_{\mathrm{a}}^{2}, \sigma_{c}^{2}$, and $\sigma_{e}^{2}$ are additive genetic, maternal permanent environmental, and residual variances, respectively. Additive coefficient of variation $\left(\mathrm{CV}_{\mathrm{A}}\right)$ was also estimated as $\mathrm{CV}_{\mathrm{A}}=100 \times \sqrt{V_{\mathrm{A}}} / \bar{x}$, where $\bar{x}$ is the sample mean. Phenotypic variances $\left(\sigma_{\mathrm{p}}^{2}\right)$ were determined as the sum of constituent components and direct heritabilities $\left(h^{2}\right)$, and maternal permanent environment effects $\left(c^{2}\right)$ were calculated as ratios of relevant variance component to $\sigma_{\mathrm{p}}^{2}$. Finally, estimates of $h^{2}$ and $c^{2}$ were used to compute total maternal effects as $t_{\mathrm{M}}=\frac{1}{4} h^{2}+c^{2}$.

\section{Results and discussion}

Least-squares means $( \pm \mathrm{SE})$ for the traits studied according to year of lambing, type of birth and age of dam at lambing in males and females are shown in Tables 3 and 4, respectively. Effects of year of birth were significant in both sexes $(P<0.01)$. Most previous studies have also reported important year effects on growth-related traits. Variation among years in growth traits arises from differences in nutrition and agro-climatic conditions which affect animals' growth (Yilmaz et al., 2007; Baneh and Hafezian, 2009; Al-Bial et al., 2012). The sex-year interaction for weaning weight and preweaning growth rate (both $P<0.01$ ) suggests greater sen- 
Table 3. Least-squares means $\pm \mathrm{SE}$ of growth traits in male Afshari lambs.

\begin{tabular}{|c|c|c|c|}
\hline \multirow[b]{2}{*}{ Factors } & \multicolumn{3}{|c|}{ Traits } \\
\hline & $\mathrm{BW}, \mathrm{kg}$ & WW, kg & GR, g day $^{-1}$ \\
\hline Year & $* *$ & $* *$ & $* *$ \\
\hline 2000 & $4.78 \pm 0.13^{\mathrm{a}}$ & $29.53 \pm 0.96^{\mathrm{a}}$ & $206 \pm 8^{a}$ \\
\hline 2001 & $4.67 \pm 0.13^{\mathrm{ab}}$ & $23.72 \pm 0.94^{b}$ & $158 \pm 7^{b}$ \\
\hline 2002 & $4.78 \pm 0.13^{\mathrm{a}}$ & $26.14 \pm 0.92^{c}$ & $177 \pm 7^{\mathrm{c}}$ \\
\hline 2003 & $4.56 \pm 0.13^{b}$ & $28.12 \pm 0.93^{\mathrm{d}}$ & $196 \pm 7^{\mathrm{d}}$ \\
\hline 2004 & $4.70 \pm 0.13^{\mathrm{a}}$ & $26.82 \pm 0.92^{\mathrm{c}}$ & $184 \pm 7^{\mathrm{c}}$ \\
\hline 2005 & $4.79 \pm 0.13^{\mathrm{a}}$ & $24.59 \pm 0.92^{b}$ & $164 \pm 7^{b}$ \\
\hline Mean & 4.71 & 26.49 & 180.8 \\
\hline Range (\% of mean) & $4.9 \%$ & $21.9 \%$ & $26.5 \%$ \\
\hline Sex-year & ns & $* *$ & $* *$ \\
\hline Birth type & $* *$ & $* *$ & $* *$ \\
\hline Single & $5.18 \pm 0.05^{b}$ & $32.93 \pm 0.41^{\mathrm{a}}$ & $231 \pm 3^{\mathrm{a}}$ \\
\hline Twin & $4.58 \pm 0.05^{\mathrm{a}}$ & $25.84 \pm 0.42^{b}$ & $177 \pm 3^{b}$ \\
\hline Adjustment for single & 1.13 & 1.27 & 1.30 \\
\hline Triplet & $4.37 \pm 0.30^{\mathrm{a}}$ & $20.71 \pm 0.67^{\mathrm{c}}$ & $135 \pm 18^{\mathrm{c}}$ \\
\hline Adjustment for single & 1.19 & 1.59 & 1.71 \\
\hline Sex-birth type & $\mathrm{ns}$ & $* *$ & $* *$ \\
\hline Dam age & $* *$ & $* *$ & $* *$ \\
\hline 2 & $4.58 \pm 0.12^{\mathrm{a}}$ & $26.19 \pm 0.64^{\mathrm{ac}}$ & $180 \pm 7^{\mathrm{ac}}$ \\
\hline 3 & $4.81 \pm 0.11^{b}$ & $27.55 \pm 0.63^{\mathrm{b}}$ & $189 \pm 6^{\mathrm{b}}$ \\
\hline 4 & $4.86 \pm 0.12^{b}$ & $27.10 \pm 0.60^{\mathrm{ab}}$ & $185 \pm 7^{\mathrm{ab}}$ \\
\hline 5 & $4.81 \pm 0.12^{\mathrm{b}}$ & $27.10 \pm 0.61^{\mathrm{ab}}$ & $185 \pm 7^{\mathrm{ab}}$ \\
\hline 6 & $4.62 \pm 0.14^{\mathrm{ab}}$ & $25.25 \pm 0.61^{\mathrm{c}}$ & $171 \pm 8^{\mathrm{c}}$ \\
\hline 7 & $4.70 \pm 0.16^{\mathrm{ab}}$ & $25.88 \pm 0.61^{\mathrm{abc}}$ & $176 \pm 9^{\mathrm{abc}}$ \\
\hline 8 & $4.49 \pm 0.31^{\mathrm{ab}}$ & $26.37 \pm 0.59^{\mathrm{abc}}$ & $180 \pm 19^{\mathrm{abc}}$ \\
\hline
\end{tabular}

BW: birth weight; WW: weaning weight; GR: growth rate; means within a factor and column that do not have a common superscript are significantly different $(P<0.05)$; ${ }^{* *}: P<0.01$; ns $=$ non-significant difference.

sitivity of male lambs to differences among years. For weaning weight of males the range in year means was $21.9 \%$ of the overall mean, whereas for females, the range in year means was only $16.6 \%$ of the overall mean. So, for postnatal growth, males were more sensitive to year effects than were females. In contrast, the range among years in birth weight was $4.9 \%$ of the mean for both sexes, and the sex-year interaction was not significant.

Type of birth had significant effects on body weight in both sexes $(P<0.01)$. Single lambs were heavier than twins and triplets in all cases, in agreement with Yilmaz et al. (2007) and Al-Bial et al. (2012). Twins and triplets weighed less at birth compared to singles. In addition, competition between lambs for milk results in lower milk consumption and, consequently, lower weight gains and weaning weights compared to singles (Baneh and Hafezian, 2009). Multiplicative adjustment factors to correct weaning weights of twins and triplets to a single-lamb basis were 1.27 and 1.59 , respectively, for males, but 1.23 and 1.42 , respectively, for females.
Thus the effect of multiple births, and especially of a triplet birth, was considerably larger in males. This was the source of the sex-type-of-birth interaction for weaning weight, and it again suggests greater environmental sensitivity in males. For birth weights, adjustments for type of birth for twin and triplet lambs were almost similar for the two sexes: 1.13 and 1.19 , respectively, for males and 1.14 and 1.22 , respectively, for females, indicating no sex-type-of-birth interaction for birth weight.

The age of the dam at lambing affected $(P<0.01)$ growth of male and female lambs. Lambs from 3- to 6-year-old ewes were heavier than lambs from 2- or > 6-year-old ewes. Our results confirmed the findings of Ganai and Pandey (2000), who reported that very young or old ewes generally produce less milk to feed their lambs and that, for this reason, lambs from second through fifth lambing were heavier than lambs from ewes at their first or greater-than-fifth lambing. For dam age, there was no obvious difference in adjustment factors 
Table 4. Least-squares means $\pm \mathrm{SE}$ of growth traits in female Afshari lambs.

\begin{tabular}{|c|c|c|c|}
\hline & \multicolumn{3}{|c|}{ Traits } \\
\hline Factors & $\mathrm{BW}, \mathrm{kg}$ & WW, kg & $\mathrm{GR}, \mathrm{g} \mathrm{day}^{-1}$ \\
\hline Year & $* *$ & $* *$ & $* *$ \\
\hline 2000 & $4.27 \pm 0.10^{\mathrm{ab}}$ & $22.46 \pm 0.64^{\mathrm{a}}$ & $151 \pm 5^{\mathrm{a}}$ \\
\hline 2001 & $4.17 \pm 0.10^{\mathrm{a}}$ & $21.17 \pm 0.63^{b}$ & $141 \pm 5^{\mathrm{b}}$ \\
\hline 2002 & $4.36 \pm 0.09^{b}$ & $23.73 \pm 0.60^{c}$ & $161 \pm 4^{\mathrm{c}}$ \\
\hline 2003 & $4.28 \pm 0.09^{\mathrm{a}}$ & $25.03 \pm 0.61^{\mathrm{d}}$ & $173 \pm 5^{\mathrm{d}}$ \\
\hline 2004 & $4.38 \pm 0.09^{b}$ & $24.38 \pm 0.61^{\mathrm{cd}}$ & $166 \pm 5^{\mathrm{cd}}$ \\
\hline 2005 & $4.38 \pm 0.09^{\mathrm{b}}$ & $23.03 \pm 0.59^{\mathrm{a}}$ & $155 \pm 5^{\mathrm{ac}}$ \\
\hline Mean & 4.31 & 23.30 & 157 \\
\hline Range (\% of mean) & $4.9 \%$ & $16.6 \%$ & $20.3 \%$ \\
\hline Sex-year & ns & $* *$ & $* *$ \\
\hline Birth type & $* *$ & $* *$ & $* *$ \\
\hline Single & $4.78 \pm 0.05^{\mathrm{b}}$ & $27.73 \pm 0.31^{\mathrm{a}}$ & $191 \pm 2^{\mathrm{a}}$ \\
\hline Twin & $4.21 \pm 0.05^{\mathrm{a}}$ & $22.57 \pm 0.32^{\mathrm{b}}$ & $152 \pm 2^{b}$ \\
\hline Adjustment for single & 1.14 & 1.23 & 1.25 \\
\hline Triplet & $3.92 \pm 0.30^{\mathrm{a}}$ & $19.59 \pm 1.42^{\mathrm{c}}$ & $130 \pm 11^{\mathrm{c}}$ \\
\hline Adjustment for single & 1.22 & 1.42 & \\
\hline Sex-birth type & ns & $* *$ & $* *$ \\
\hline Dam age & ** & $* *$ & $* *$ \\
\hline 2 & $4.32 \pm 0.08^{\mathrm{a}}$ & $23.40 \pm 0.52^{\mathrm{a}}$ & $158 \pm 4^{\mathrm{a}}$ \\
\hline 3 & $4.43 \pm 0.08^{b}$ & $24.22 \pm 0.52^{b}$ & $165 \pm 4^{\mathrm{b}}$ \\
\hline 4 & $4.46 \pm 0.08^{b}$ & $24.56 \pm 0.52^{b}$ & $167 \pm 4^{\mathrm{b}}$ \\
\hline 5 & $4.47 \pm 0.09^{b}$ & $24.41 \pm 0.61^{b}$ & $166 \pm 5^{\mathrm{ab}}$ \\
\hline 6 & $4.32 \pm 0.11^{\mathrm{abc}}$ & $23.79 \pm 0.74^{\mathrm{abc}}$ & $162 \pm 5^{\mathrm{abc}}$ \\
\hline 7 & $4.10 \pm 0.13^{c}$ & $22.18 \pm 0.94^{\mathrm{c}}$ & $151 \pm 7^{\mathrm{ac}}$ \\
\hline 8 & $4.02 \pm 0.25^{\mathrm{abc}}$ & $20.52 \pm 1.602^{c}$ & $137 \pm 12^{\mathrm{ac}}$ \\
\hline
\end{tabular}

BW: birth weight; WW: weaning weight; GR: growth rate; means within a factor and column that do not have a common superscript are significantly different $(P<0.05)$; ${ }^{* *}: P<0.01$;

$\mathrm{ns}=$ non-significant difference.

between sexes for either birth or weaning weights, and therefore no dam age-sex interactions was identified.

As shown in Table 2, male lambs were $6.6 \%$ heavier at birth, had $14.4 \%$ higher growth rates, and consequently were $16.0 \%$ heavier at weaning compared to female lambs. The $\mathrm{M} / \mathrm{F}$ ratios, which were used to express the magnitude of SSD (Lovich and Gibbons, 1992) were, respectively, 1.07, 1.14 and 1.15 for BW, WW, and GR. These estimates showed low levels of SSD for these traits. In addition, our findings regarding levels of SSD were closer to those reported by Polak and Frynta (2009) in domestic (1.41), compared to wild (1.67), species of sheep.

Differences between male and female lambs reflect difference in the endocrine environment, and associated differences in nutrient requirements, between the sexes. Regulatory mechanisms controlling growth hormone (GH) secretion are sexually dimorphic (Gatford et al., 1996; Jaffe et al., 1998). Gatford et al. (1996) reported that sex significantly affected patterns of changes in circulating growth hormone,
IGF-I (insulin-like growth factor), and IGFPB-3 (insulinlike growth factor binding protein) concentrations in growing prepubertal lambs. Mean plasma GH concentrations, $\mathrm{GH}$ pulse amplitude, and integrated plasma $\mathrm{GH}$ concentrations were greater in rams than in ewes at a variety of different ages. They concluded that differences in circulating patterns and concentrations of GH, IGF-I, and IGFBP-3 may arise from the action of steroids during sexual differentiation and before puberty. Steroids such as testosterone and estrogen affect the growth of males and females differentially. In males, testosterone is produced in large quantities, whereas in females estrogen and progesterone predominate. Testosterone stimulates muscle growth by affecting the rate of protein synthesis, protein breakdown, and the net gain or loss of muscle protein (Mateescu and Thonney, 2002). In addition, exposure to high estrogen levels limits growth of long bones and consequently affects body size in females.

Results of univariate animal models including data from lambs of both sexes are shown in Table 5. Heritability es- 
Table 5. Estimates of variance components and genetic parameters from a univariate analyses with both sexes included and with fitting of a fixed effect of lamb sex.

\begin{tabular}{lrcccccc}
\hline Trait & Log L & $V_{\mathrm{A}}$ & $V_{C}$ & $V_{E}$ & $V_{\mathrm{P}}$ & $h^{2}$ & $c^{2}$ \\
\hline BW, kg & 184.716 & 0.101 & 0.056 & 0.159 & 0.317 & $0.32(0.07)$ & $0.18(0.04)$ \\
WW, kg & -2564.870 & 2.475 & 1.133 & 11.262 & 14.871 & $0.17(0.06)$ & $0.08(0.03)$ \\
GR, g day $^{-1}$ & -5434.932 & 109.23 & 73.97 & 741.60 & 924.81 & $0.12(0.06)$ & $0.08(0.03)$ \\
\hline
\end{tabular}

Log L: the logarithm of the converged likelihood function; $V_{\mathrm{A}}$ : additive genetic variance; $V_{C}$ : maternal permanent

environmental variance; $V_{E}$ : residual variance; $V_{\mathrm{P}}$ : phenotypic variance; $h^{2}$ : direct heritability; $c^{2}:$ maternal environmental effect; BW: birth weight; WW: weaning weight; GR: growth rate.

Table 6. Estimates of variance components and genetic parameters in male and female lambs.

\begin{tabular}{|c|c|c|c|c|c|c|c|c|c|}
\hline Trait and sex & $V_{\mathrm{A}}$ & $V_{C}$ & $V_{E}$ & $V_{\mathrm{P}}$ & $V_{\mathrm{A}} / V_{E}$ & $h^{2}$ & $c^{2}$ & $\mathrm{CV}_{\mathrm{A}}$ & $t_{\mathrm{M}}$ \\
\hline \multicolumn{10}{|l|}{$\mathrm{BW}, \mathrm{kg}$} \\
\hline M & 0.131 & 0.060 & 0.144 & 0.337 & 0.91 & $0.39(0.11)^{\mathrm{b}}$ & $0.18(0.05)^{b}$ & 7.28 & 0.28 \\
\hline $\mathrm{F}$ & 0.088 & 0.067 & 0.147 & 0.303 & 0.60 & $0.29(0.08)^{b}$ & $0.22(0.05)^{b}$ & 6.37 & 0.29 \\
\hline \multicolumn{10}{|l|}{ WW, kg } \\
\hline M & 2.457 & 2.228 & 11.886 & 16.573 & 0.21 & $0.15(0.08)^{\mathrm{b}}$ & $0.13(0.06)^{b}$ & 5.17 & 0.17 \\
\hline $\mathrm{F}$ & 2.588 & 0.501 & 8.836 & 11.927 & 0.22 & $0.22(0.08)^{\mathrm{b}}$ & $0.04(0.04)^{b}$ & 6.07 & 0.10 \\
\hline \multicolumn{10}{|l|}{ GR, $\mathrm{g} \mathrm{day}^{-1}$} \\
\hline M & 109.55 & 165.56 & 768.20 & 1043.3 & 0.14 & $0.11(0.07)^{\mathrm{b}}$ & $0.16(0.05)^{b}$ & 4.98 & 0.19 \\
\hline $\mathrm{F}$ & 117.08 & 26.99 & 585.05 & 729.13 & 0.20 & $0.16(0.07)^{\mathrm{b}}$ & $0.04(0.04)^{b}$ & 5.94 & 0.08 \\
\hline
\end{tabular}

$V_{\mathrm{A}}$ : additive genetic variance; $V_{C}$ : maternal permanent environmental variance; $V_{E}:$ residual variance; $V_{\mathrm{P}}$ : phenotypic variance; $h^{2}:$ direct heritability; $c^{2}$ : maternal environmental effect; $\mathrm{CV}_{\mathrm{A}}$ : additive coefficient of variation; $t_{\mathrm{M}}\left(\frac{1}{4} h^{2}+c^{2}\right)$ : total maternal effect; BW: birth weight; WW: weaning weight; GR: growth rate; M: male; F: female; identical superscripts within a column and trait indicate that the sexes did not differ significantly based on approximate $95 \%$ confidence intervals.

timates for BW, WW, and GR were $0.32,0.17$, and 0.12 , respectively. Maternal permanent environmental effects $\left(c^{2}\right)$ were largest for BW (0.18) and lower (0.08) for WW and GR. Heritability estimates for WW and GR were quite close to literature averages reported for these traits in models that fitted maternal effects, but the heritability estimate for BW was somewhat larger than the literature average (Safari et al., 2005). Maternal effects in our analyses were anticipated to approximate the sum of the additive and permanent environmental maternal effects but were generally smaller than averages reported for this sum in the literature (Safari et al., 2005).

Estimates of variance components and genetic parameters from the bivariate analysis are presented in Table 6. In most cases, estimates of additive genetic variances were higher in females, while estimates of maternal permanent environmental and residual variances were higher in males. As expected, results from the univariate model in Table 5 were generally intermediate to, but not simple averages of, the sex-specific estimates in Table 6, indicating that differences between the sexes are reflecting variation in overall (co)variance structures. Our results regarding additive genetic variance were in agreement with Gudex et al. (2009) - who estimated greater additive genetic variance in females than males for weaning and post-weaning body weights in Australian Coopworth, Poll Dorset and White Suffolk sheep breeds - but contra- dicted Milner et al. (2000), who found higher additive genetic variance in male lambs for body weight, hind leg length and incisor breadth in a free-living population of Soay sheep. High values for $V_{C}$ and $V_{E}$ in males for WW and GR were consistent with the hypothesis of greater environmental sensitivity in males. This observation was consistent with the generally lower prenatal survival rates observed for male lambs (e.g., Dalton et al., 1980; Riggio et al., 2008), even after accounting for the potential confounding influence of sex differences in birth weights (Hatcher et al., 2009), meaning that, even though males are heavier and may seem more robust than females, they also seem to be more sensitive to environmental stresses. Accordingly, abortion cases and mortality rate should be higher in males compared to females, a phenomenon which has also been documented in human studies (Cunningham et al., 2010). The ratio of $V_{\mathrm{A}} / V_{E}$ in both the sexes was maximum for BW. However, in males, the ratio was close to unity. If this ratio were low, phenotypic response to selection would be slower because environmental variation could offset phenotypic response to selection even when there is high additive variation in the trait of interest.

Estimates of $h^{2}$ for BW, WW and GR were $0.39,0.15$ and 0.11 , respectively, in males and $0.29,0.22$ and 0.16 , respectively, in females. Heritability estimates for growth-related traits in sheep vary considerably among breeds and populations and depend on the method of estimation. However, cur- 
rent estimates were in the range reported in different breeds of sheep by Safari et al. (2005). The higher heritability estimates for WW and GR in females were consistent with results of Gudex et al. (2009), who reported higher heritability estimates for post-natal body weights in female lambs of the Australian Coopworth, Poll Dorset and White Suffolk breeds, although in most cases the differences were not significant. By contrast, estimated values of $h^{2}$ and $\mathrm{CV}_{\mathrm{A}}$ for BW in males were, respectively, $34 \%$ (0.39 vs. 0.29$)$ and $14 \%$ (7.3 vs. $6.4 \%$ ) greater than that in females. Houle (1992) proposed that the "coefficient of additive genetic variance" is often more informative than the heritability. The $\mathrm{CV}_{\mathrm{A}}$ scales the component of additive genetic variance by the trait mean instead of the total variance and so is not confounded with the magnitude of other variance components (Kruuk et al., 2000). The " $\sqrt{V_{\mathrm{A}}} / \bar{x}$ " ratio measures "variability" or capability to change, while the ratio " $V_{\mathrm{A}} / V_{\mathrm{P}}$ " measures "heritability" of the trait. Our estimates of $\mathrm{CV}_{\mathrm{A}}$ show more additive genetic variability, i.e., more potential for response to selection, in BW of male compared to female lambs. In both sexes, estimates of $c^{2}$ and $t_{\mathrm{M}}$ were approximately the same for male and female lambs at birth, but for weaning weight $t_{\mathrm{M}}$ and $c^{2}$ were higher for males. However, approximate standard errors and resulting $95 \%$ confidence intervals for both direct and maternal variance components did not indicate significant differences between sexes. A previous study by Gudex et al. (2009) on sexual dimorphism in sheep generally agrees that differences between male and female lambs in estimates of direct and maternal variances are not significant. These results may reflect a lack of sexual selection in domestic animals which has resulted in decreased SSD (Polak and Frynta, 2009).

Genetic $\left(r_{a(\mathrm{~m}, \mathrm{f})}\right)$ and maternal permanent environmental correlations $\left(r_{\mathrm{c}(\mathrm{m}, \mathrm{f})}\right)$ between sexes were 0.986 and 0.723 for BW, 0.995 and 0.983 for WW, and 0.995 and 0.966 for GR, respectively, which highlighted $\mathrm{BW}$ as somewhat dimorphic at the level of the maternal effects $(P<0.15$; Table 7$)$. Gudex et al. (2009) estimated $r_{a(\mathrm{~m}, \mathrm{f})}$ for weaning, post-weaning, yearling and hogget weights in Coopworth, Poll Dorset and White Suffolk breeds of sheep. Their estimates of $r_{a(\mathrm{~m}, \mathrm{f})}$ ranged from 0.59 for yearling weight in White Suffolk to 0.97 for weaning weight in Poll Dorset and White Suffolk breeds. Based on a literature survey, Poissant et al. (2010) founded that, except for fitness-related traits, genetic correlations between homologous traits expressed in males and females were predominantly large and positive. Because of genotype-environment interactions, $r_{a(\mathrm{~m}, \mathrm{f})}$ is environmentspecific, and, due to differences in allele frequencies, estimates of $r_{a(\mathrm{~m}, \mathrm{f})}$ are also population-specific (Falconer, 1989; Poissant et al., 2010). Large and positive $r_{a(\mathrm{~m}, \mathrm{f})}$ show that growth-related traits in males and females are controlled by the same genes and that selection on males (i.e., in prospective sires) will improve both male and female body weights.

If the traits of interest were controlled by genes that are differently expressed in lambs of the two sexes, the $r_{a(\mathrm{~m}, \mathrm{f})}$
Table 7. Correlations between random effects estimated in different sexes.

\begin{tabular}{|c|c|c|}
\hline Trait & $r_{a(\mathrm{~m}, \mathrm{f})}$ & $r_{\mathrm{c}(\mathrm{m}, \mathrm{f})}$ \\
\hline $\mathrm{BW}, \mathrm{kg}$ & 0.986 & 0.727 \\
\hline $\mathrm{WW}, \mathrm{kg}$ & 0.995 & 0.983 \\
\hline GR, g day $^{-1}$ & 0.995 & 0.966 \\
\hline
\end{tabular}

$r_{a(\mathrm{~m}, \mathrm{f})}:$ genetic correlation between males and

females; $r_{\mathrm{c}(\mathrm{m}, \mathrm{f})}$ : maternal permanent

environmental correlation between males and

females; BW: birth weight; WW: weaning

weight; GR: growth rate.

would be significantly less than 1.0, and, in such a situation, divergent selection could be used to diverge male and female phenotypes toward desirable outcomes. For example, the relationship between lamb birth weight and perinatal survival is curvilinear, with survival rates commonly optimized at intermediate optimum birth weights (Hatcher et al., 2009). Sex-specific selection could thus allow increases in birth weights in females, to improve perinatal survival, but without changing birth weights in males, to avoid increases in difficult births. Deviations of $r_{a(\mathrm{~m}, \mathrm{f})}$ from unity may result from activation of loci on sex chromosomes. Wittenburg et al. (2011) quantified effects of sex-linked genes on birth weights of Landrace piglets. They partitioned the additive effects into autosomal and gonosomal effects and reported that the Y chromosome contributed significantly to genetic variation in birth weight, though the effect of the X chromosome was not significant. Such Y- or X-linked loci activation has been documented in other species (Lindholm et al., 2006; Willmore et al., 2009). However, $r_{a(\mathrm{~m}, \mathrm{f})}$ in our data were very close to 1.0 for all measured variables, apparently precluding an important role for nonautosomal genes.

Departure of $r_{\mathrm{c}(\mathrm{m}, \mathrm{f})}$ from unity would indicate differential maternal effects of the dam on male and female offspring. In our analyses, maternal effects would include both additive maternal effects controlled by genes carried by the dam and permanent environmental effects of the dam that are presumably mediated by early-life influences on the dam and retained across lambings. Values of $r_{a(\mathrm{~m}, \mathrm{f})}$ for weaning weight and preweaning gains were very close to 1.0 , whereas the correlation of maternal effects on BW across sexes was considerably lower $(0.73)$, though still not significantly different from $1.0(P<0.15)$. The potential for sex-specific maternal effects at either an additive genetic or permanent environmental level is intriguing given the potential for lifetime, or even intergenerational, fetal programming events and epigenetic modifications in females that can affect future progeny birth weights in mammalian species (Drake and Walker, 2004). Differential effects of such modifications on birth weights of lambs of different sexes have, to our knowledge, not been documented but would be consistent with the role of IGF-2 in placental and fetal growth and the paternal 
and maternal imprinting of IGF-2 and its receptor, respectively, in sheep (Lawrence et al., 2012).

In conclusion, male lambs were heavier at birth, grew more rapidly to weaning, and were therefore heavier at weaning compared to female lambs. Effects of lamb sex on weaning weight and preweaning rate of gain interacted with effects of birth year and birth type. These interactions, and the generally greater residual and maternal variances observed for male lambs, suggest greater environmental sensitivity of male, compared to female, lambs. Additive genetic variances for preweaning gains and weaning weights were somewhat larger in female lambs. However, additive genetic correlations for body weight traits between male and female lambs were large, suggesting that these traits were controlled by similar genes. Opportunities for sex-specific selection to create or modify sexual-size dimorphism in sheep therefore appear limited and cannot be used to diverge phenotypes for body weights between the sexes.

Acknowledgements. We thank M. P. Eskandarinasab, the head of the Department of Animal Science of the Zanjan University and H. S. Mohammadi, the manager of the Afshari sheep experimental flock, who provided us the data used in this study. Also, we wish to thank two anonymous referees for their comments and suggestions.

Edited by: A.-E. Freifrau von Tiele-Winckler

Reviewed by: two anonymous referees

\section{References}

Al-Bial, A., Singh, J., Singh, D. P., and Niwas, R.: Environmental and genetic factors on growth traits of Black Bangal sheep in Yemen, The Bioscan., 7, 185-188, 2012.

Albuquerque, L. G. and Meyer, K.: Estimates of covariance functions for growth from birth to 630 days of age in Nelore cattle, J. Anim. Sci., 79, 2776-2789, 2001.

Badyaev, A. V.: Male and female growth in sexually dimorphic species: harmony, conflict, or both?, Comments. Theor. Biol., 7, 11-33, 2002.

Baneh, H. and Hafezian, H.: Effects of environmental factors on growth traits in Ghezel sheep, Afr. J. Biotechnol., 8, 2903-2907, 2009.

Cunningham, F., Leveno, K., Bloom, S., Hauth, J., Rouse, D., and Spong, C.: Williams Obstetrics, 23rd Edition, Mc Graw-Hill, New York, USA, 2010.

Dalton, D. C., Knight, T. W., and Johnson, D. L.: Lamb survival in sheep breeds on New Zealand hill country, New Zeal. J. Agr. Res., 23, 167-173, 1980.

Drake, A. J. and Walker, B. R.: The intergenerational effects of fetal programming: non-genomic mechanisms for the inheritance of low birth weight and cardiovascular risk, J. Endocrinol., 180, 116, 2004.

Dunshea, F. R.: Sexual dimorphism in growth of suckling and growing pigs, Asian-Australasian J. Anim., 14, 1610-1615, 2001.

Eason, J. M., Schwartz, G., Shirley, K. A., and English, A. W.; Investigation of sexual dimorphism in the rabbit masseter muscle showing different effects of androgen deprivation in adult and young adult animals, Arch. Oral Biol., 45, 683-690, 2000.

Eskandarinasab, M. P., Ghafouri-Kesbi, F., and Abbasi, M. A.: Different models for evaluation of growth traits and Kleiber ratio in an experimental flock of Iranian fat-tailed Afshari sheep, J. Anim. Breed. Genet., 127, 26-33, 2010.

Falconer, D. S.: Introduction to quantitative genetics, 3rd ed., Wiley, New York, USA, 1989.

Ganai, T. A. S. and Pandey, R. S.: Factors influencing pre- and postweaning survivability of exotic sheep, Indian. J. Anim. Sci., 70, 316-318, 2000.

Gatford, K. L., Fletcher, T. P., Clarke, I. J., Owens, P. C., Quinn, K. J., Walton, P. E., Grant, P. A., Hosking, B. J., Egan, A. R., and Ponnampalam, E. N.: Sexual dimorphism of circulating Somatotropin, Insulin-Like Growth Factor I and II, Insulin-Like Growth Factor Binding Proteins, and Insulin: relationships to growth rate and carcass characteristics in growing lambs. J. Anim. Sci., 74, 1314-1325, 1996.

Gudex, B. W., Condro, C., Marshal, K., and van der Werf, J. H. J.: The genetics of sexual dimorphism in sheep, Proc. Assoc. Advance. Anim. Breed. Genet., 18, 14-17, 2009.

Hatcher, S., Atkins, K. D., and Safari, E.: Phenotypic aspects of lamb survival in Australian Merino sheep, J. Anim. Sci., 87, 2781-2790, 2009.

Houle, D.: Comparing evolvability and variability of quantitative traits, Genetics, 130, 195-204, 1992.

Jaffe, C. A., Ocampo-Lim, B., Guo, W., Krueger, K., Sugahara, I., DeMott-Friberg, R., Bermann, M., and Barkan, A. L.: Regulatory mechanisms of growth hormone secretion are sexually dimorphic, J. Clinic. Invest., 102, 153-164, 1998.

Kruuk, L. E. B., Clutton-Brock, T. H., Slate, J., Pemberton, J. M., Brotherstone, S., and Guinness, F. E.: Heritability of fitness in a wild mammal population, P. Natl. Acad. Sci. USA, 97, 698-703, 2000.

Lawrence, T. L. J., Fowler, V. R., and Novakofski, J. E.: Growth of Farm Animals, 3rd Edition, CABI, Wallingford, UK, 2012.

Lindholm, A., Hunt, J., and Brooks, R.: Where do all the maternal effects go? Variation in offspring body size through ontogeny in the live-bearing fish Poeciliaparae, Biol. Letters, 2, 586-589, 2006.

Lovich, J. E. and Gibbons, J. W.: A review of techniques for quantifying sexual size dimorphism, Growth Develop. Aging, 56, 269281, 1992.

Maniatis, G., Demiris, N., Kranis, A., Banos, G., and Kominakis, A.: Genetic analysis of sexual dimorphism of body weight in broilers, J. Appl. Genet., 54, 61-70, 2013.

Mateescu, R. G. and Thonney, M. L.: Gene expression in sexually dimorphic muscles in sheep, J. Anim. Sci., 80, 1879-1887, 2002.

Meyer, K.: DFREML Version 3.1: user notes, 2000.

Milner, J. M., Pemberton, J. M., Brotherstone, S., and Albon, S. D.: Estimating variance components and heritabilities in the wild: a case study using the "animal model" approach, J. Evolution Biol., 13, 804-813, 2000.

NRC, National Research Council: Nutrient Requirements of Sheep, 6th rev. edn., National Academy Press, Washington, DC, USA, 1985.

Poissant, J., Wilson, A. J., and Coltman, D. W.: Sex-specific genetic variance and the evolution of sexual dimorphosm: A systematic 
review of cross-sex genetic correlation, Evolution, 64, 97-107, 2010.

Poissant, J. M., Wilson, A. J., Festa-Bianchet, M., Hogg, J. T., and Coltman, D. W.: Quantitative genetics and sex-specific selection on sexually dimorphic traits in bighorn sheep, P. Roy. Soc. BBiol. Sci., 275, 623-628, 2008.

Polak, J. and Frynta, D.: Sexual size dimorphism in domestic goats, sheep, and their wild relatives, Biol. J. Linn. Soc., 98, 872-883, 2009.

Polak, J. and Frynta, D.: Patterns of sexual size dimorphism in cattle breeds support Rensch's rule, Evol. Ecol., 24, 1255-1266, 2010.

Rensch, B.: Die Abhängigkeit der relativen Sexualdifferenz von der Körpergröße, Bonn Zool. Beitr., 1, 58-69, 1950.

Riggio, V., Finocchiaro, R., and Bishop, S. C.: Genetic parameters for early lambs survival and growth in Scottish Blackface sheep, J. Anim. Sci., 86, 1758-1764, 2008.
Safari, E., Fogarty, N. M., and Gilmour, A. R.: A review of genetic parameter estimates for wool, growth, meat and reproduction traits in sheep, Livest. Prod. Sci., 92, 271-289, 2005.

SAS: User's Guide, version 9, SAS Institute, Cary, NC, USA, 2004. Willmore, K. E., Roseman, C. C., Rogers, J., Richtsmeier, J. T., and Cheverud, J. M.: Genetic variation in Baboon caraniofacial sexual dimorphism, Evolution, 63, 799-806, 2009.

Wittenburg, D., Teuscher, F., and Reinsch, N.: Statistical tools to detect genetic variation for a sex dimorphism in piglet birth weight, J. Anim. Sci., 89, 622-629, 2011.

Yilmaz, O., Denk, H., and Bayram, D.: Effects of lambing season, sex and birth type on growth performance in Norduz lambs, Small. Ruminant Res., 68, 336-339, 2007. 